\title{
Germination of phagocytosed $E$. cuniculi spores does not significantly contribute to parasitophorous vacuole formation in $\mathbf{J 7 7 4}$ cells
}

\author{
Johanna Orlik • Karin Böttcher • Uwe Groß • \\ Wolfgang Bohne
}

Received: 18 December 2009/Accepted: 4 January 2010/Published online: 28 January 2010

(C) The Author(s) 2010. This article is published with open access at Springerlink.com

\begin{abstract}
The obligate intracellular microsporidia have developed a unique invasion mechanism to infect their host cells. Spores explosively evert a tube-like structure and extrude the infectious spore content through this organelle into the host cell. Spores from species of the genus Encephalitozoon were also shown to be efficiently internalized by phagocytosis, which led to the hypothesis that spore germination from inside a phagosome might contribute to the infection process. Here, we challenge this hypothesis by quantifying Encephalitozoon cuniculi infection rates of $\mathrm{J} 774$ cells that were incubated with the phagocytosis inhibitor cytochalasin D. We demonstrate that the invasion rate in cytochalasin D-treated cells is identical to untreated controls, although phagocytic uptake of $E$. cuniculi spores was less than $10 \%$ of control samples. This study suggests that germination of phagocytosed spores is not a significant infection mode for E. cuniculi.
\end{abstract}

Microsporidia are a group of unicellular, obligate intracellular eukaryotes, which were shown to be of fungal origin (Hirt et al. 1999; Lee et al. 2008). On the one hand, microsporidia have reduced their genome size, their gene

Johanna Orlik and Karin Böttcher contributed equally to this work

J. Orlik $\cdot$ K. Böttcher $\cdot$ U. Groß $\cdot$ W. Bohne $(\triangle)$

Institute of Medical Microbiology, University of Göttingen,

Kreuzbergring 57,

37075 Göttingen, Germany

e-mail: wbohne@gwdg.de content, and also their metabolism to a minimum and can thus be considered as one of the most extreme eukaryotic parasites (Katinka et al. 2001). On the other hand, these organisms have evolved a sophisticated invasion mechanism which is unique in nature. The infectious agent is an environmentally resistant spore, which contains a long, coiled, tube-like organelle. Invasion is initiated by a sudden rise of the osmotic pressure, which leads to the explosive eversion of the polar tube, a process known as germination (Bigliardi and Sacchi 2001). Immediately after germination, the infectious sporoplasm is extruded through the polar tube and can establish an infection, if it gets localized into the cytosol of a host cell. According to the conventional model of microsporidia infection, the tip of the polar tube needs to penetrate the host cell cytoplasma membrane for a successful infection; however, our recent data suggest that for Encephalitozoon cuniculi an invagination of the plasma membrane instead of a penetration might occur (Rönnebaumer et al. 2008). After invasion, species of the genus Encephalitozoon replicate inside a parasitophorous vacuole and differentiate from meronts into sporonts and finally into mature spores.

A remarkable feature of E. cuniculi spores is their ability to induce their phagoyctic uptake even in non-professional phagocytes (Couzinet et al. 2000). Spore phagocytosis per se is not a route that leads to a successful infection and the usual fate of a spore-containing phagosome is the fusion with endosomal vesicles and maturation into phagolysosomes (Couzinet et al. 2000; Leitch et al. 2005). However, based on the phagocytic internalization, an escape mecha- 
nism was proposed that would establish an alternative invasion route (Franzen 2004). According to this model, the internalized spore germinates from inside the phagosome and injects the sporoplasma either in the cytosol of the same or in that of an adjacent cell. Indeed, immunofluorescence analysis revealed the presence of germinated spores inside phagosomes (Franzen et al. 2005); however, it is difficult to judge from fixed samples whether these germinations would really lead to the formation of new parasitophorous vacuoles with growing meronts inside. We tested in this study the contribution of this hypothetical invasion mode for E. cuniculi.

To investigate the putative contribution of spore germination out of phagosomes to the overall formation of parasitophorous vacuoles (PVs), it was important to utilize tissue culture conditions which resulted in an efficient phagocytic uptake of $E$. cuniculi spores. We compared various cell types for their potential to internalize E. cuniculi spores with the aim to identify conditions that resulted in a high ratio of phagocytosed spores in relation to the infection rate, measured as total number of meront-containing PVs. Various host cells were incubated with $E$. cuniculi spores and subjected to differential immunofluorescence staining (Heesemann and Laufs 1985) at $20 \mathrm{~h}$ post-infection in order to discriminate between internal, phagocytosed, and external adhesive spores (Fig. 1a). Parallel samples underwent conventional immunofluorescence staining with the meront-specific antibody mAb 6G2 (Fasshauer et al. 2005) in order to detect established PVs (Fig. 1b). The highest ratio of phagocytosed spores in relation to the infection rate was found in LPS stimulated J774 cells (Fig. 2).

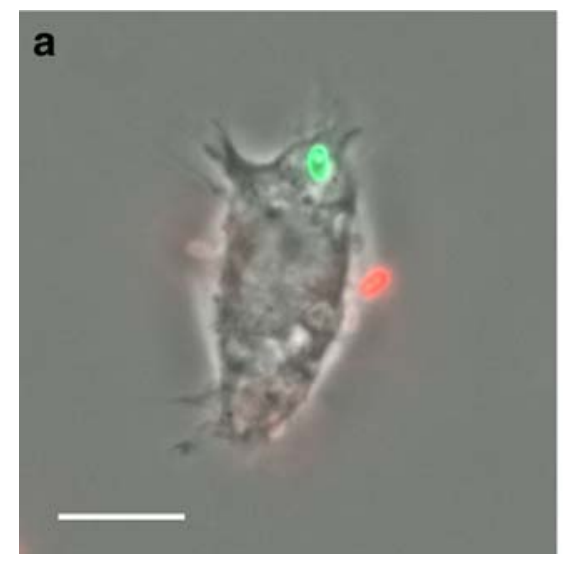

Fig. 1 Detection of meronts and phagocytosed spores. a Differential immunofluorescence staining was applied to distinguish internalized from extracellular spores. J774 cells were cultured on cover slides, incubated with E. cuniculi spores and fixed $20 \mathrm{~h}$ later with $4 \%$ paraformaldehyd in PBS for $30 \mathrm{~min}$. Samples were washed twice with PBS and incubated with mAb 11A1 (1:100 in PBS), which detects the spore wall protein SWP1 (Bohne et al. 2000), followed by incubation with a Cy3-conjugated anti-mouse $\operatorname{IgG}$ (1:500 in PBS). Afterwards, cells were permeabilized in $0.25 \%$ TritonX100/PBS for $20 \mathrm{~min}$. The

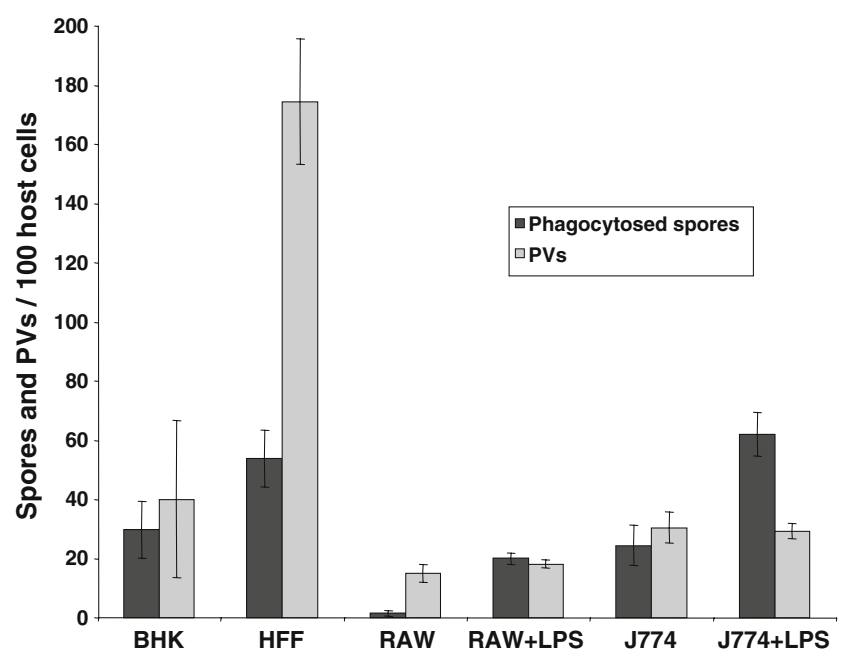

Fig. 2 E. cuniculi phagocytosis and infection rates in various host cells. Baby hamster kidney cells, human foreskin fibroblasts, and two monocyte/macrophage cell lines (RAW and J774 cells) were cultured in 24-well plates on cover slides and incubated with $5 \times 10^{6}$ E. cuniculi spores. LPS was added to the indicated samples at a final concentration of $300 \mathrm{ng} / \mathrm{ml}$ simultaneously to infection. At 20$\mathrm{h}$ post-infection, phagosome formation was determined by differential $\mathrm{mAb} 11 \mathrm{~A} 1$ immunofluorescence staining and the amount of formed PVs was determined by mAb 6G2 staining. The total number of internalized spores and PVs was determined from 100 host cells per cover slide. The results are given as means \pm standard deviations from three independent experiments, each performed in duplicates

Cytochalasin D treatment was used on LPS stimulated and non-stimulated $\mathrm{J} 774$ cells in order to inhibit phagocytosis. Cytochalasin D was added at a final concentration of $1 \mu \mathrm{M}$ simultaneously to E. cuniculi infection and left in the tissue culture medium until fixation of the samples $20 \mathrm{~h}$

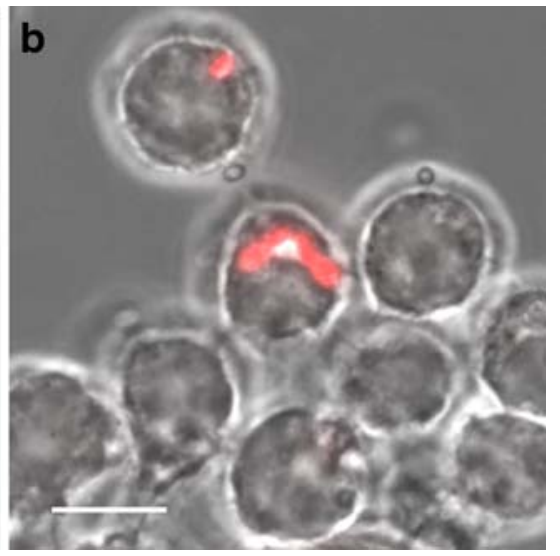

incubation step with $\mathrm{mAb} 11 \mathrm{~A} 1$ was repeated, followed by $\mathrm{IgG}$ detection with a Cy2-conjugated anti-mouse $\operatorname{IgG}$ (1:300 in PBS). Fluorescence microscopy revealed a red color (Cy3) for extracellular spores and a green color (Cy2) for intracellular spores. b Detection of meronts inside parasitophorous vacuoles. Samples were fixed and permeabilized as described above and incubated with mAb 6G2, which recognizes an antigen expressed in meronts (Fasshauer et al. 2005), followed by $\operatorname{IgG}$ detection with a Cy3-conjugated anti-mouse IgG. Size bars are $10 \mu \mathrm{m}$ 
post-infection. Parallel samples were subjected either to differential immunofluorescence staining to determine the phagocytosis rate or to $\mathrm{mAb} 6 \mathrm{G} 2$ staining in order to detect meront-containing PVs. The morphology of J774 cells was found to be unaltered during the time course of the experiment, indicating that the applied cytochalasin D concentration is non-toxic for the host cells. Cytochalasin $\mathrm{D}$ treatment resulted in a decrease of internalized spores to less than $10 \%$ of control samples in both, LPS stimulated and non-stimulated $\mathrm{J} 774$ cells, demonstrating that inhibition of phagocytosis was successful (Fig. 3a). In contrast, the number of formed PVs was not influenced by cytochalasin $\mathrm{D}$ treatment (Fig. 3b). This suggests that spore germination
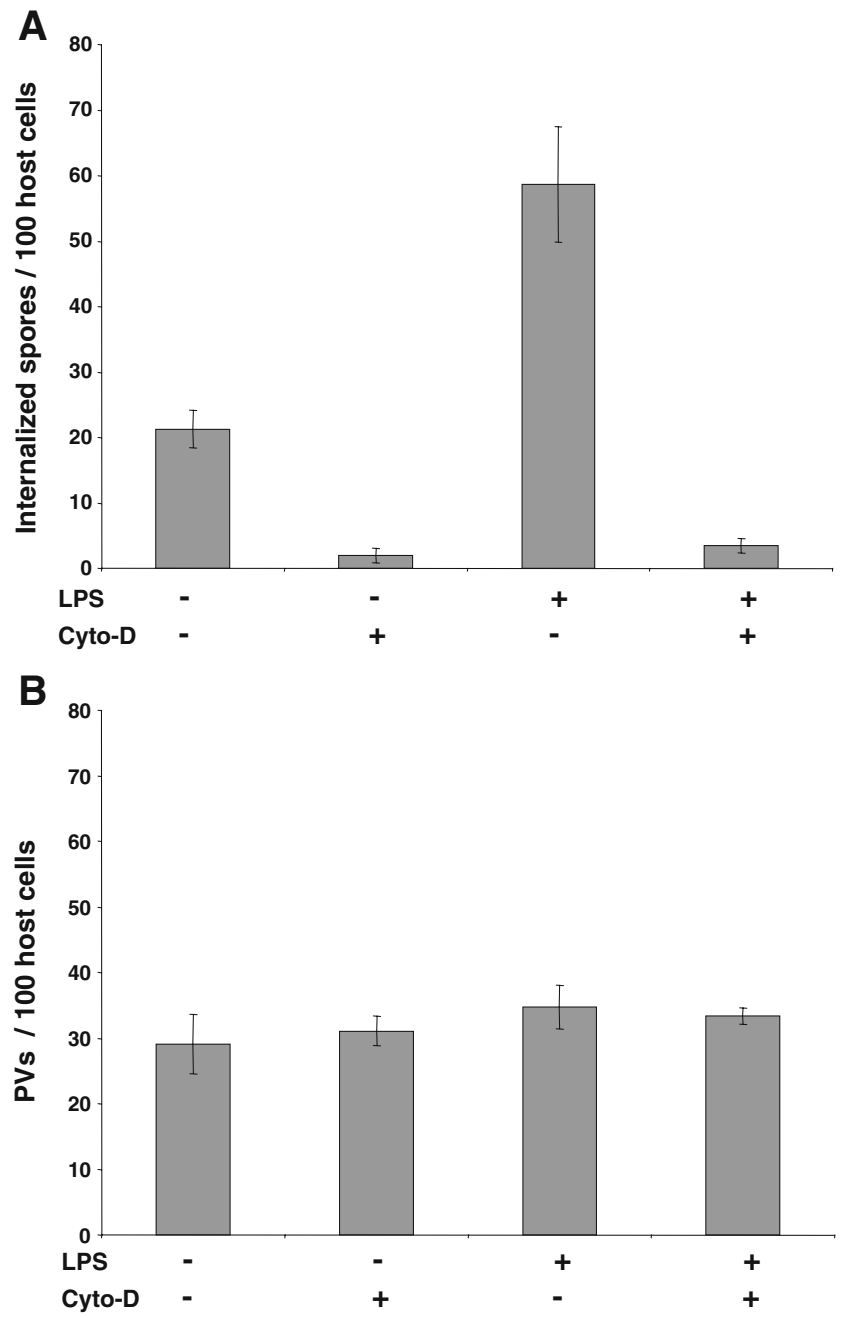

Fig. 3 Infection rates are not reduced in cytochalasin D-treated J774 cells. J774 cells were cultured, stimulated with LPS, and infected with E. cuniculi as described above (see Fig. 2). Cytochalasin D was added simultaneously with $E$. cuniculi spores at a final concentration of $1 \mu \mathrm{M}$. The number of internalized spores and of formed PVs was determined from 100 host cells per cover slide as described above (see Fig. 2). The results are given as means \pm standard deviations from two experiments, each performed in duplicates. Phagocytic internalization of E. cuniculi spores was inhibited in cytochalasin D-treated samples, while the amount of established PVs was unchanged under these conditions out of phagosomes does not significantly contribute to the formation of PVs under the applied conditions. The by-fardominanting infection mode is thus germination from extracellular spores, even in J774 cells which possess a high-phagocytic capacity. We cannot exclude with these experiments that spore germination within phagosomes with subsequent PV formation is completely lacking; however, if it occurs, its contribution to infection is negligible under the applied conditions.

Acknowledgments This study has been supported by a grant from the Deutsche Forschungsgemeinschaft, DFG (GR906/11-2).

Open Access This article is distributed under the terms of the Creative Commons Attribution Noncommercial License which permits any noncommercial use, distribution, and reproduction in any medium, provided the original author(s) and source are credited.

\section{References}

Bigliardi E, Sacchi L (2001) Cell biology and invasion of the microsporidia. Microbes Infect 3:373-379

Bohne W, Ferguson DJ, Kohler K, Gross U (2000) Developmental expression of a tandemly repeated, glycine- and serine-rich spore wall protein in the microsporidian pathogen Encephalitozoon cuniculi. Infect Immun 68:2268-2275

Couzinet S, Cejas E, Schittny J, Deplazes P, Weber R, Zimmerli S (2000) Phagocytic uptake of Encephalitozoon cuniculi by nonprofessional phagocytes. Infect Immun 68:6939-6945

Fasshauer V, Gross U, Bohne W (2005) The parasitophorous vacuole membrane of Encephalitozoon cuniculi lacks host cell membrane proteins immediately after invasion. Eukaryot Cell 4:221-224

Franzen C (2004) Microsporidia: how can they invade other cells? Trends Parasitol 20:275-279

Franzen C, Muller A, Hartmann P, Salzberger B (2005) Cell invasion and intracellular fate of Encephalitozoon cuniculi (Microsporidia). Parasitology 130:285-292

Heesemann J, Laufs R (1985) Double immunofluorescence microscopic technique for accurate differentiation of extracellularly and intracellularly located bacteria in cell culture. J Clin Microbiol 22:168-175

Hirt RP, Logsdon JM Jr, Healy B, Dorey MW, Doolittle WF, Embley TM (1999) Microsporidia are related to fungi: evidence from the largest subunit of RNA polymerase II and other proteins. Proc Natl Acad Sci USA 96:580-585

Katinka MD, Duprat S, Cornillot E, Metenier G, Thomarat F, Prensier G, Barbe V, Peyretaillade E, Brottier P, Wincker P, Delbac F, El Alaoui H, Peyret P, Saurin W, Gouy M, Weissenbach J, Vivares CP (2001) Genome sequence and gene compaction of the eukaryote parasite Encephalitozoon cuniculi. Nature 414:450-453

Lee SC, Corradi N, Byrnes EJ 3rd, Torres-Martinez S, Dietrich FS, Keeling PJ, Heitman J (2008) Microsporidia evolved from ancestral sexual fungi. Curr Biol 18:1675-1679

Leitch GJ, Ward TL, Shaw AP, Newman G (2005) Apical spore phagocytosis is not a significant route of infection of differentiated enterocytes by Encephalitozoon intestinalis. Infect Immun 73:7697-7704

Rönnebaumer K, Gross U, Bohne W (2008) The nascent parasitophorous vacuole membrane of Encephalitozoon cuniculi is formed by host cell lipids and contains pores which allow nutrient uptake. Eukaryot Cell 7:1001-1008 